\title{
Perinatal and infant mortality in term and preterm births among women with type 1 diabetes
}

\author{
I. Eidem • S. Vangen • K. F. Hanssen • S. E. Vollset • \\ T. Henriksen • G. Joner • L. C. Stene
}

Received: 1 April 2011 /Accepted: 1 July 2011 /Published online: 25 August 2011

(C) Springer-Verlag 2011

\begin{abstract}
Aims/hypothesis The aim of this study was to estimate the risks of adverse birth outcomes such as stillbirth, infant death, preterm birth and pre-eclampsia in women with type 1 diabetes, compared with the background population. We further aimed to explore the risks of adverse birth outcomes in preterm and term deliveries separately.

Methods By linkage of two nationwide registries, the Medical Birth Registry of Norway and the Norwegian Childhood Diabetes Registry, we identified 1,307 births among women with pregestational type 1 diabetes regis-
\end{abstract}

Electronic supplementary material The online version of this article (doi:10.1007/s00125-011-2281-7) contains peer-reviewed but unedited supplementary material, which is available to authorised users.

I. Eidem $\cdot$ G. Joner

Department of Paediatrics, Oslo University Hospital Ullevål,

Oslo, Norway

I. Eidem $(\bowtie) \cdot$ S. Vangen $\cdot$ L. C. Stene

Division of Epidemiology, Norwegian Institute of Public Health, $\mathrm{Pb} .4404$ Nydalen,

NO-0403 Oslo, Norway

e-mail: Ingvild.eidem@fhi.no

S. Vangen

Norwegian Resource Centre for Women's Health, Department of Gynaecology and Obstetrics, Oslo University Hospital,

Rikshospitalet,

Oslo, Norway

K. F. Hanssen

Department of Endocrinology, Oslo University Hospital Aker,

Oslo, Norway

K. F. Hanssen - T. Henriksen

Institute of Clinical Medicine, Medical Faculty,

University of Oslo,

Oslo, Norway tered in the Diabetes Registry, and 1,161,092 births in the background population during the period 1985-2004. The ORs with $95 \%$ CIs for adverse outcome among women with type 1 diabetes vs the background population were estimated using logistic regression.

Results The OR for stillbirth ( $\geq 22$ weeks of gestation) was 3.6 (95\% CI 2.5, 5.3), and for perinatal death (stillbirth or death in the first week of life) it was 2.9 (95\% CI 2.0, 4.1). The OR for infant death (first year of life) was 1.9 (95\% CI $1.1,3.2)$. For preterm birth $(<37$ weeks of gestation) and pre-eclampsia the ORs were $4.9(95 \%$ CI $4.3,5.5)$ and 6.3

S. E. Vollset

Medical Birth Registry, Norwegian Institute of Public Health, Bergen, Norway

\section{S. E. Vollset}

Department of Public Health and Primary Health Care,

University of Bergen,

Bergen, Norway

T. Henriksen

Section of Obstetrics, Oslo University Hospital,

Rikshospitalet,

Oslo, Norway

\section{G. Joner}

Department of Health Management and Health Economics, Institute of Health and Society, University of Oslo,

Oslo, Norway 
(95\% CI 5.5, 7.2), respectively. When preterm and term deliveries were analysed separately, the excess risk of stillbirth and infant death in women with diabetes was confined to term deliveries.

Conclusions/interpretation Pregestational type 1 diabetes was associated with a considerably higher risk of adverse pregnancy outcomes, including infant death, compared with the background population. A novel finding of the study was that the increased risk was confined to term births.

Keywords Birth outcome - Gestational age - Infant death . Perinatal death $\cdot$ Pre-eclampsia $\cdot$ Pregnancy $\cdot$ Preterm birth . Stillbirth · Type 1 diabetes

\section{Abbreviation \\ LMP Last menstrual period}

\section{Introduction}

Despite substantial advances in the treatment of type 1 diabetes over recent decades and focus on the necessity of good care before and during pregnancy for women with the disease, most research studies indicate that women with pregestational type 1 diabetes still have a considerably higher risk of pregnancy complications and adverse pregnancy outcome compared with the background population [1-6]. The risk of stillbirth or perinatal death has, according to recent studies, varied between three and six times the risk in women without diabetes [7]. Few population-based studies have investigated the risk of infant death.

While it is well established that perinatal mortality is strongly increased in preterm deliveries [8], and that preterm delivery is much more common in type 1 diabetes pregnancies $[1,3,4]$, few studies have investigated the relative risk of perinatal mortality in women with type 1 diabetes separately in term and preterm births.

The main objective of this study was to estimate the risk of stillbirth, infant death, preterm delivery and preeclampsia in women with pregestational type 1 diabetes in Norway compared with the background population. We further aimed to explore the risk of adverse birth outcome in preterm and term deliveries separately.

\section{Methods}

Subject and study design All births in Norway in the period 1985-2004 occurring after 22 weeks of gestation were included in the study. Since 1967 the Medical Birth Registry of Norway has recorded all births in the country, with data on labour, the newborn child and the health of the mother before and during pregnancy. To ensure a valid diagnosis of type 1 diabetes, we linked data in the Medical Birth Registry to the Norwegian Childhood Diabetes Registry, through the unique personal identification number given to all Norwegians. With a high degree of ascertainment, the Diabetes Registry has registered incident type 1 diabetes cases diagnosed throughout Norway before age 15 over certain time periods: prospectively since 1989 [9] and retrospectively for incident cases during the period 1973 1982 [10]. In addition, cases diagnosed at age 15-29 years were registered retrospectively for the period 1978-1982 [11]. Our study population included 1,307 babies born during the period 1985-2004 to a mother registered with type 1 diabetes in the Diabetes Registry. Births during the same period to a mother without type 1 diabetes $(n=$ $1,161,092)$ constituted the background population. Because the Diabetes Registry only includes incident cases for young persons and for certain periods, our study population includes approximately one third of all births by women with type 1 diabetes in Norway during the study period. Data on infant deaths were derived from the Cause of Death Registry, and information on maternal education, immigrant status and country of origin was obtained from Statistics Norway (www.ssb.no).

Outcome variables Stillbirth was defined as death of the fetus before or during labour. Perinatal death was defined as stillbirth or death during the first 7 days of life. Neonatal and early neonatal death were defined as death of a live born infant during the first 28 or 7 days of life, respectively, and infant death as death during the first year of life. Gestational age was primarily calculated based on the first day of the last menstrual period (LMP), to ensure a uniform measure throughout the study period (ultrasound-based gestational age was not registered in the Birth Registry until 1999, and was thus missing for about two thirds of the study population.) If LMP data were missing, we used ultrasound-based gestational age, if available. If no data on gestational age was available, births were included in the study if the birthweight was $500 \mathrm{~g}$ or more. Preterm and very preterm birth were defined as delivery before 37 or 32 completed weeks of gestation, respectively. When the births were grouped into preterm and term deliveries, post term deliveries were included in the term group. Pre-eclampsia was defined as any pre-eclampsia registered in the Birth Registry, including eclampsia and HELLP syndrome $(\mathrm{H}$, haemolysis; EL, elevated liver enzymes; LP, low platelet count). The registration was based on free text until 1999 and pre-coded check boxes or free text combined since 1999. According to national guidelines, the diagnostic criteria for pre-eclampsia include blood pressure $\geq 140$ / $90 \mathrm{mmHg}$ after at least 20 weeks of gestation, and 
proteinuria $\geq 0.3 \mathrm{~g} /$ day, or $\geq 1+$ on a urine dipstick on two occasions [12]. Non-spontaneous deliveries were deliveries started by healthcare workers, either with medication/ amniotomy, or with Caesarean section. Low Apgar score was defined as a score of less than 7 at 5 min after delivery.

Potential confounding variables Parity (number of previous births) was divided into para $0,1,2,3$ and $\geq 4$. Maternal age was divided into $<20,20-29,30-34,35-39$ and $\geq 40$ years of age. Educational level was the highest education achieved by the mother in 2004, and was divided into three categories: less than 12 years of school, 12 years of school, or exam at college or university. Ethnic origin was divided into two groups, depending on whether or not the woman giving birth was a first or second generation immigrant from a country outside Europe (or from Turkey). Year of delivery, sex of child, and marital status (married/ cohabitant vs living alone) were other possible confounders adjusted for. When using gestational age for adjustment in multivariate analyses, it was categorised into the following groups (completed weeks): 22-27, 28-31, 32-34, 35-36, $37,38,39,40,41,42-45(6.6 \%$ had missing data on gestational age).

Statistical analyses We used logistic regression in SPSS to estimate ORs with $95 \%$ CIs of birth outcomes in pregnancies with type 1 diabetes compared with the background population before and after adjusting for the confounding factors listed above. For rare outcomes (those occurring in approximately $<5-10 \%$ of births in all subgroups), the OR is a good approximation to the relative risk. All confounding factors except year of delivery were used as categorical variables in the analyses. For small samples (expected counts below 5), we derived $\mathrm{p}$ values from Fisher's exact test (two sided). The statistical programme STATA was used to make the density plot for distribution of births over gestational age in days (Fig. 1).

\section{Results}

Mothers with type 1 diabetes were on average slightly younger at delivery and had slightly lower parity than those without, and they were more often of European origin (Table 1). Differences were otherwise minor.

Stillbirth and perinatal death occurred approximately three times more often in pregnancies among women with type 1 diabetes compared with the background population (Table 2). The risk of infant death within the diabetes group was twice that of the background population, and stillbirth or infant death combined occurred three times more often among women with diabetes. Estimates were little affected by adjustment for potential confounding factors.

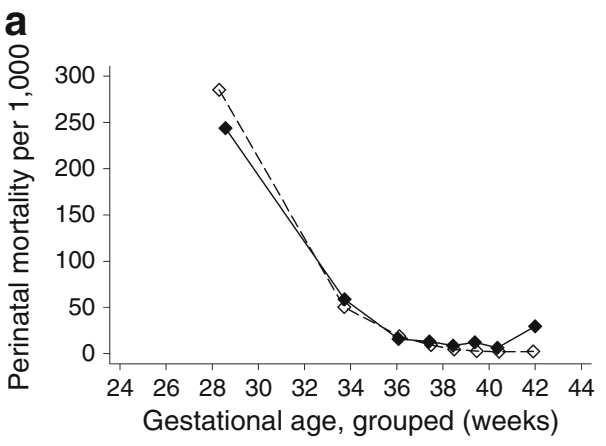

b
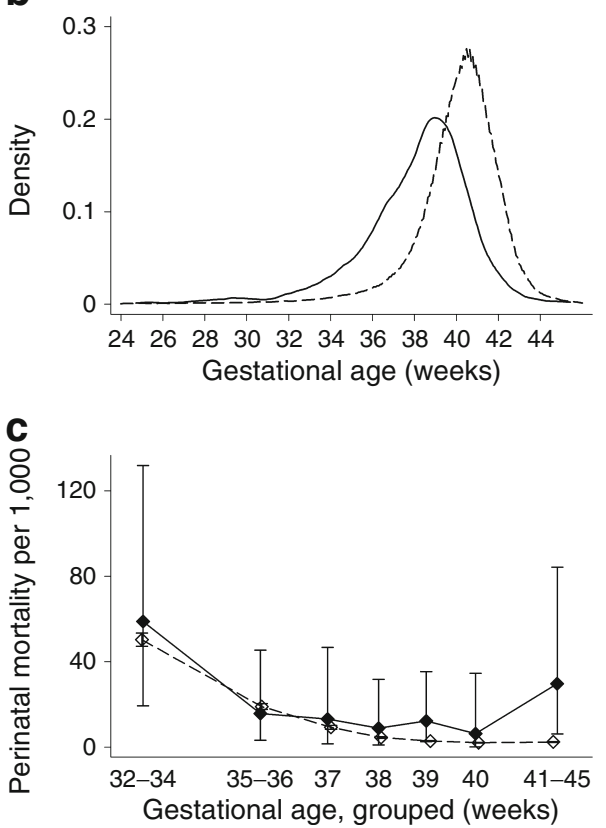

Fig. 1 Perinatal mortality by gestational age at birth in women with type 1 diabetes (black diamonds and solid lines) and in the background population (white diamonds and dashed lines), for births of 22 or more completed weeks (a) and restricted to 32 or more completed weeks of gestation (c). Diamonds are placed at the mean gestational age in weeks within the following groups: 22-31, 32-34, $35-36,37,38,39,40,41-45$. b shows the distribution of gestational age in the diabetes group (black line) and in the background population (dashed line). Information on gestational age was missing for $6.6 \%$ of the total population. Error bars represent $95 \%$ CIs

Twenty six per cent of the women with type 1 diabetes delivered preterm (Table 2), of which $42 \%$ spontaneously preterm (Table 3). Almost 20\% in the diabetes group were registered with pre-eclampsia, and close to $60 \%$ experienced a non-spontaneous start of labour (Table 2). Median gestational age was 38.4 weeks ( 270 days, interquartile range 258-278 days) among women with type 1 diabetes, and 40.2 weeks (282 days, interquartile range 274 289 days) in the background population. Gestational age may be viewed as an intervening variable between type 1 diabetes and adverse outcomes, and after adjusting for gestational age, the OR for stillbirth was 1.8 (95\% CI 1.2, 
Table 1 Characteristics of women with pregestational type 1 diabetes, and the background population, giving birth in Norway in the period 1985-2004

\begin{tabular}{|c|c|c|}
\hline Variable & $\begin{array}{l}\text { Type } 1 \text { diabetes } \\
(n \text { births }=1,307)\end{array}$ & $\begin{array}{l}\text { Background population } \\
(n \text { births }=1,161,092)\end{array}$ \\
\hline $\begin{array}{l}\text { Age at diagnosis of type } 1 \\
\text { diabetes (years), median } \\
\text { (IQ range) }\end{array}$ & $11(8-13)$ & - \\
\hline$<10(\%)$ & 39.7 & - \\
\hline $10-14(\%)$ & 44.8 & - \\
\hline$\geq 15(\%)$ & 15.5 & - \\
\hline $\begin{array}{l}\text { Duration of diabetes (years), } \\
\text { median (IQ range) }\end{array}$ & $17(12-21)$ & - \\
\hline$<10(\%)$ & 14.3 & - \\
\hline $10-19(\%)$ & 55.9 & - \\
\hline$\geq 20(\%)$ & 29.8 & - \\
\hline $\begin{array}{l}\text { Age at delivery (years), } \\
\text { median (IQ range) }\end{array}$ & $27(24-30)$ & $28(25-32)$ \\
\hline$<20(\%)$ & 4.2 & 3.6 \\
\hline $20-29(\%)$ & 64.1 & 57.0 \\
\hline $30-34(\%)$ & 24.9 & 27.7 \\
\hline $35-39(\%)$ & 6.4 & 10.2 \\
\hline$\geq 40(\%)$ & 0.4 & 1.6 \\
\hline \multicolumn{3}{|l|}{ Parity $(\%)$} \\
\hline Para 0 & 50.2 & 41.6 \\
\hline Para 1 & 34.5 & 35.3 \\
\hline Para 2 & 12.4 & 16.6 \\
\hline Para 3 & 2.3 & 4.5 \\
\hline Para 4 or more & 0.6 & 1.9 \\
\hline \multicolumn{3}{|l|}{ Educational level $^{\mathrm{a}}(\%)$} \\
\hline Less than 12 years of school & 34.7 & 35.0 \\
\hline Completed 12 years of school & 32.1 & 29.7 \\
\hline Education at college or university & 33.2 & 35.3 \\
\hline European origin $(\%)^{\mathrm{b}}$ & 99.9 & 94.4 \\
\hline Married or cohabitants (\%) & 89.5 & 91.4 \\
\hline Sex of baby (\% boys) & 49.9 & 51.4 \\
\hline
\end{tabular}

${ }^{\text {a }}$ Percent among mothers with data on education. Data were missing for $4.6 \%$ of the total population

${ }^{\mathrm{b}}$ Defined as women who are not first or second generation immigrants from a country outside Europe, or from Turkey

IQ, interquartile

2.8), for perinatal death $1.6(95 \%$ CI 1.1, 2.3), and for stillbirth or infant death 1.6 (95\% CI 1.1, 2.2; data not shown in table).

Table 3 shows the risk of mortality and other pregnancy outcome separately for preterm and term births. Results show that the excess mortality in births among women with type 1 diabetes was confined to term deliveries, with little or no difference in mortality between births among women with and without type 1 diabetes when analyses were restricted to preterm births (test for interaction for perinatal death: $p<0.001)$. Similar results were found when excluding births registered with major malformations (not shown). The result for perinatal death is explored in more detail in
Fig. 1. Restricting the analyses to deliveries between 37 and 40 completed weeks gave an OR for stillbirth of $3.6(95 \%$ CI 1.7, 7.7), for perinatal death of 2.7 (95\% CI 1.3, 5.7), and for stillbirth or infant death of 2.2 (95\% CI 1.6, 4.3; not shown in tables).

More than half of the deliveries among women with diabetes had a non-spontaneous start, both in term and preterm group. Among women delivering spontaneously to term $(n=353), 0.8 \% \quad(n=3)$ experienced perinatal death, which is a five times higher risk than that in the corresponding background population $(p=0.02$, Fisher's exact test). All three women had an LMP-based gestational age beyond 40 weeks of gestation. Women with diabetes delivering non-spontaneously to term had a non-significant OR for perinatal death of 1.6 compared with the background population $(p=0.19)$. Among preterm deliveries, there was no significant difference in the risk of perinatal death between women with and without diabetes, neither in women delivering spontaneously, nor in women delivering non-spontaneously (the estimated, non-significant ORs for women with diabetes were $<1$ for all adverse outcomes, data not shown in tables).

Among women with pre-eclampsia, there was no case of adverse outcome in the term diabetes group. In women with pre-eclampsia delivering preterm, there was no significant difference in adverse outcome between women with and without diabetes (OR for perinatal death in relation to the background population was $0.51, p=0.59$ [Fisher's exact test]).

Stillbirths and infant deaths among women with type 1 diabetes are listed case-wise in electronic supplementary material (ESM) Table 1, with information on gestational age. Ten of 24 stillbirths (42\%) with known gestational age occurred after 37 weeks of gestation, and the median gestational age was 35 weeks among stillbirths and 34 weeks among all pre- or postnatal deaths. In 60\% (24/ $40)$, the fetus was a girl. In eight cases there was one or more serious malformations registered. Births after 1998 were often registered with gestational age based on both LMP and ultrasound. For four of the seven deaths with both sources available, there was a considerable difference (about 2 weeks) in gestational age depending on the source used. The ultrasound-based gestational age was the shorter of the two.

The sample size was not sufficient for detailed study of time trends in adverse outcome among women with type 1 diabetes, but when dividing the study period into three time periods the risks of stillbirth, perinatal death, and stillbirth or infant death were significantly higher among women with type 1 diabetes in all periods (Fig. 2). Over the three periods, the risks declined significantly among the background population (tests for trend: $p<0.001$ ). Among women with diabetes, the proportions with adverse out- 
Table 2 Risk of fetal and infant death, preterm birth and pre-eclampsia in pregnancies with pregestational type 1 diabetes, relative to the Norwegian background population (ORs)

\begin{tabular}{|c|c|c|c|c|c|c|c|c|}
\hline \multirow[t]{2}{*}{ Outcome $^{\mathrm{a}}$} & \multicolumn{3}{|c|}{$\begin{array}{l}\text { Births in women with type } 1 \text { diabetes } \\
(n=1,307)\end{array}$} & \multicolumn{3}{|c|}{$\begin{array}{l}\text { Background population } \\
(n=1,161,092)\end{array}$} & \multicolumn{2}{|c|}{ Odds ratio $(95 \% \mathrm{CI})$} \\
\hline & $\begin{array}{l}\text { Affected } \\
\qquad(n)\end{array}$ & $\begin{array}{c}\text { Not affected } \\
(n)\end{array}$ & $\begin{array}{l}\text { Affected } \\
\quad(\%)\end{array}$ & $\begin{array}{l}\text { Affected } \\
\quad(n)\end{array}$ & $\begin{array}{l}\text { Not affected } \\
\qquad(n)\end{array}$ & $\begin{array}{l}\text { Affected } \\
\quad(\%)\end{array}$ & Unadjusted & Adjusted $^{\mathrm{b}}$ \\
\hline Stillbirth & 27 & 1,280 & 2.1 & 6,790 & $1,154,302$ & 0.58 & $3.6(2.5,5.3)$ & $3.8(2.6,5.6)$ \\
\hline Perinatal death & 32 & 1,275 & 2.4 & 9,941 & $1,151,151$ & 0.86 & $2.9(2.0,4.1)$ & $3.1(2.2,4.4)$ \\
\hline Early neonatal death ${ }^{\mathrm{c}}$ & 5 & 1,275 & 0.39 & 3,151 & $1,151,118$ & 0.27 & $1.4(0.60,3.5)$ & $1.5(0.64,3.7)$ \\
\hline Neonatal death ${ }^{\mathrm{c}}$ & 6 & 1,274 & 0.47 & 3,925 & $1,150,344$ & 0.34 & $1.4(0.62,3.1)$ & $1.5(0.66,3.3)$ \\
\hline Infant death ${ }^{c}$ & 13 & 1,267 & 1.0 & 6,279 & $1,147,990$ & 0.54 & $1.9(1.1,3.2)$ & $2.0(1.2,3.5)$ \\
\hline Stillbirth or infant death & 40 & 1,267 & 3.1 & 13,069 & $1,148,023$ & 1.1 & $2.8(2.0,3.8)$ & $3.0(2.2,4.1)$ \\
\hline Preterm birth 37 weeks ${ }^{\mathrm{d}}$ & 316 & 883 & 26.4 & 74,269 & $1,010,383$ & 6.8 & $4.9(4.3,5.5)$ & $5.0(4.4,5.7)$ \\
\hline Preterm birth 32 weeks ${ }^{\mathrm{d}}$ & 41 & 1,158 & 3.4 & 15,104 & $1,069,548$ & 1.4 & $2.5(1.8,3.4)$ & $2.6(1.9,3.5)$ \\
\hline Pre-eclampsia & 249 & 1,058 & 19.1 & 41,810 & $1,119,282$ & 3.6 & $6.3(5.5,7.2)$ & $6.0(5.2,6.9)$ \\
\hline Non-spontaneous delivery ${ }^{\mathrm{e}}$ & 772 & 535 & 59.1 & 200,039 & 961,053 & 17.2 & $6.9(6.2,7.7)$ & $6.9(6.1,7.7)$ \\
\hline
\end{tabular}

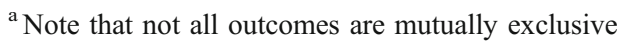

${ }^{\mathrm{b}}$ Adjusted for parity, maternal age, year of delivery, sex of child, maternal educational level, European or other origin, and marital status

${ }^{\mathrm{c}}$ Per cent among live births

${ }^{\mathrm{d}}$ Among births with registered gestational age: $n=1,199$ in the diabetes group and 1,084,652 in the background population

${ }^{\mathrm{e}}$ Among these, Caesarean sections made up $64.5 \%$ in the diabetes group and $42.7 \%$ in the background population

comes were also lower at the end of the study period than at the beginning, but test for trend was significant only for stillbirth or infant death. We found no association between duration of diabetes and adverse outcome after adjusting for maternal age and year of birth (data not shown).

\section{Discussion}

In addition to documenting a three to four times increased risk of stillbirth and perinatal death among women with type 1 diabetes compared with the background population, the novel findings in this study were a significantly higher risk of death during the first year of life, and that the increased risk of adverse outcome was limited to term births.

Strengths and limitations of the study Our study population consists of births at any hospital throughout Norway during 1985-2004. Linkage to the nationwide type 1 diabetes registry secured a valid diagnosis of type 1 diabetes. Thus the results are not influenced by incorrect or unspecific coding of diabetes, nor by selection bias due to selective participation to studies or difference in hospital profiles. The design of the study resulted in a relatively low median age at diagnosis and thereby a relatively long median duration of diabetes at delivery, although all age groups were represented. However, as we found no association between adverse outcome and duration of diabetes within our population, we believe the relatively long median duration has not caused any major bias. Our data did not include clinically relevant data such as glycated haemoglobin and microalbuminuria. We could not, therefore, explore the correlation between birth outcomes and these factors in our population. The large sample allowed for the study of rare outcomes such as infant death, and for exploring the risk of death in subgroups such as term and preterm births.

Comparison with other studies The three- to fourfold increased risk of stillbirth and perinatal death for women with type 1 diabetes observed in our study is comparable with the better results from population-based studies in other countries [7]. Intensive neonatal care has continuously improved over the past years, making the chance of surviving the first days of life better. We therefore aimed to include death during the whole first year of life (infant death) in the outcomes studied, thus going beyond the focus of most studies in the field. We found a doubled risk of infant death in women with diabetes compared with the background population, and a tripled risk of stillbirth or infant death. The current study is, as far as we know, the first to show a statistically significant excess risk of infant death in women with type 1 diabetes. The magnitude of this result is in accordance with estimates from Great Britain and Sweden, which indicated a doubled or tripled risk of infant death without reaching statistical significance [13-16]. 
Table 3 Birth outcomes in preterm and term deliveries ${ }^{\mathrm{a}}$

\begin{tabular}{|c|c|c|c|c|c|}
\hline \multirow[t]{2}{*}{ Outcome } & \multirow[t]{2}{*}{ Type 1 diabetes } & \multirow[t]{2}{*}{ Background population } & \multicolumn{3}{|l|}{ OR $(95 \% \mathrm{CI})$} \\
\hline & & & Unadjusted & Adjusted $^{\mathrm{b}}$ & Adjusted $^{\mathrm{c}}$ \\
\hline \multicolumn{6}{|l|}{ Preterm births ( $<37$ weeks) } \\
\hline GA, median (IQ range) & $247(237-254)$ & $246(229-254)$ & & & \\
\hline Non-spontaneous delivery & $185(58.5)$ & $24,117(32.5)$ & $2.9(2.3-3.7)$ & & \\
\hline Pre-eclampsia & $109(34.5)$ & $8,979(12.1)$ & $3.8(3.0-4.8)$ & & \\
\hline Stillbirth & $14(4.4)$ & $4,126(5.6)$ & $0.79(0.5-1.4)$ & $0.82(0.5-1.4)$ & $1.1(0.6-2.0)$ \\
\hline Perinatal death & $18(5.7)$ & $6,045(8.1)$ & $0.68(0.4-1.1)$ & $0.71(0.4-1.1)$ & $1.0(0.6-1.7)$ \\
\hline Infant death ${ }^{\mathrm{d}}$ & $8(2.6)$ & $2,818(4.0)$ & $0.65(0.3-1.3)$ & $0.67(0.3-1.4)$ & $1.1(0.5-2.2)$ \\
\hline Stillbirth or infant death & $22(7.0)$ & $6,944(9.3)$ & $0.73(0.5-1.1)$ & $0.75(0.5-1.2)$ & $1.1(0.7-1.7)$ \\
\hline Apgar $<7$ at $5 \min ^{\mathrm{d}}$ & $12(4.0)$ & $4,074(5.8)$ & $0.67(0.4-1.2)$ & $0.68(0.4-1.2)$ & $0.90(0.5-1.6)$ \\
\hline \multicolumn{6}{|l|}{ Births at term $(\geq 37$ weeks $)$} \\
\hline GA, median (IQ range) & $274(268-281)$ & $283(276-290)$ & & & \\
\hline Non-spontaneous delivery & $530(60.0)$ & $162,898(16.1)$ & $7.8(6.8-8.9)$ & & \\
\hline Pre-eclampsia & $125(14.2)$ & $30,129(3.0)$ & $5.4(4.4-6.5)$ & & \\
\hline Stillbirth & $10(1.1)$ & $2,111(0.21)$ & $5.5(2.9-10.2)$ & $5.8(3.1-10.9)$ & $4.0(2.1-7.5)$ \\
\hline Perinatal death & $11(1.2)$ & $2,991(0.30)$ & $4.2(2.3-7.7)$ & $4.6(2.5-8.3)$ & $3.3(1.8-5.9)$ \\
\hline Infant death ${ }^{\mathrm{d}}$ & $5(0.6)$ & $2,814(0.28)$ & $2.1(0.85-5.0)$ & $2.3(0.96-5.6)$ & $1.9(0.8-4.6)$ \\
\hline Stillbirth or infant death & $15(1.7)$ & $4,925(0.49)$ & $3.5(2.1-5.9)$ & $3.9(2.3-6.5)$ & $2.9(1.8-4.9)$ \\
\hline Apgar $<7$ at $5 \min ^{\mathrm{d}}$ & $14(1.6)$ & $7,817(0.78)$ & $2.1(1.2-3.5)$ & $2.1(1.2-3.5)$ & $2.0(1.2-3.4)$ \\
\hline
\end{tabular}

Data are given as $n(\%)$, unless indicated otherwise

Preterm births: type 1 diabetes $n=316$, background population $n=74,269$; births at term: type 1 diabetes $n=883$, background population $n=1,010,383$

${ }^{a}$ Births without a registered gestational age are excluded

${ }^{\mathrm{b}}$ Adjusted for parity, maternal age, year of delivery, sex of child, maternal educational level, European or other origin, and marital status

${ }^{\mathrm{c}}$ Adjusted for the same factors as in ${ }^{\mathrm{b}}$, plus gestational age categorised into ten groups

${ }^{\mathrm{d}}$ Per cent among live births

GA, gestational age; IQ, interquartile

The current study was, to our knowledge, the first since a study in the mid-1980s [14] to present data on mortality for term and preterm deliveries separately. This Swedish study of 914 births examined both late fetal death and infant death in subgroups of preterm and term births, but found no significant differences between women with diabetes and controls in either of the groups. No data on gestational age within the term group were presented, and we find it difficult to speculate on reasons for the apparent conflict with our results.

Our finding of $19 \%$ risk of pre-eclampsia was similar to the reported risk of pre-eclampsia among Danish women with type 1 diabetes in the 1990s (18\%) [3], but was higher than results from Sweden [1] and the Netherlands [4]. Diagnostic criteria for pre-eclampsia diagnosis are, however, not necessarily alike between countries and studies [17], and while the Swedish study seemed to use similar criteria to ours and allowed 1+ for proteinuria if a dipstick was used, the Danish study required 2+, and the Dutch study was based on $24 \mathrm{~h}$ values only. To what extent such differences influence the results is unknown. Our finding that one third of the women with diabetes delivering preterm had a diagnosis of pre-eclampsia was in accordance with results from two single-centre studies from Israel (using similar criteria as in the current study) and the USA, the latter from the 1980s [18, 19].

Considerations and implications The preterm birth rate in the diabetes group was $26 \%$, much higher than in the background population (7\%). Generally, preterm delivery is emphasised to be the most important single factor in perinatal mortality [20], and mild and moderate preterm births (32-36 weeks of gestation) are alone responsible for an important fraction of infant deaths in general populations [21]. Based on these factors, an excess risk of perinatal and infant death in women with diabetes could theoretically be due to a higher proportion of preterm births, which are at higher risk than births to term. If the risks within each stratum of preterm and term births were similar for women with and without diabetes, there would still be a higher risk in the total group of women with diabetes, if the rate of preterm births was higher among them than in the 
a

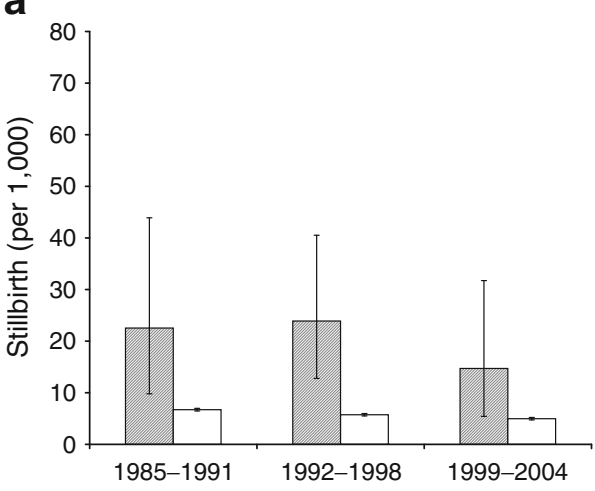

b

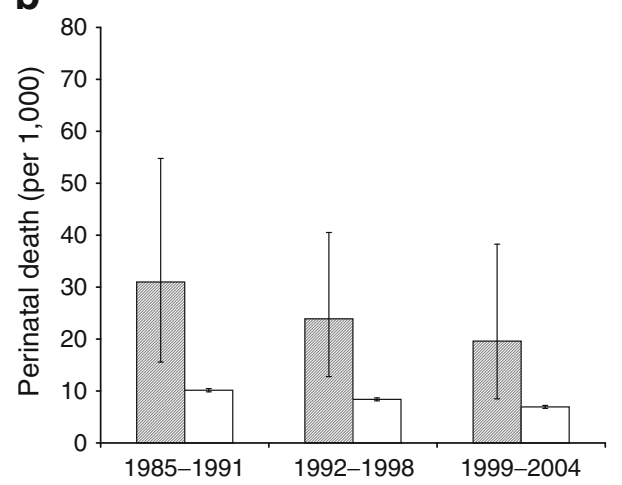

C

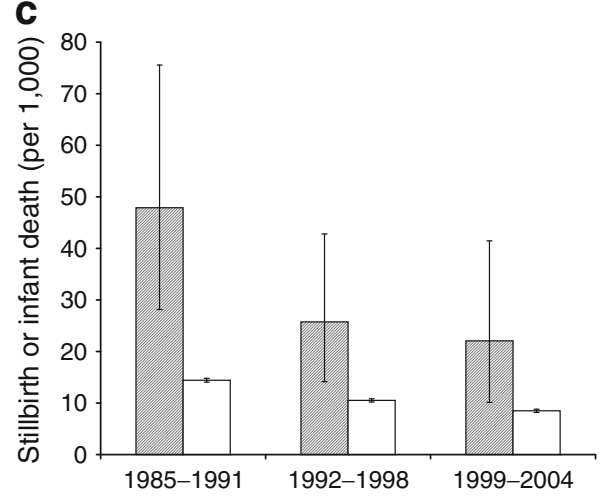

Fig. 2 The proportion with stillbirth (a), perinatal death (b), and stillbirth or infant death (c) in births among women with type 1 diabetes (grey bars) and the background population (white bars), divided into three time periods. The risks were significantly higher among women with diabetes than in the background population in each time period. Tests for trend within the background population had $p<0.001$ for (a), (b) and (c). Tests for trend within the diabetes group had $p=0.43$ (a), $p=0.32$ (b) and $p=0.045$ (c). Error bars represent $95 \%$ CIs

background population. Our finding of an increased risk in women with diabetes delivering to term shows that a higher proportion of preterm births in the diabetes group is not the whole explanation of the total excess risk. It seems that late stillbirth, also after 37 weeks of gestation, still plays a role in the persistent higher risk of adverse pregnancy outcome in women with type 1 diabetes.
The observed lack of excess risk in women with diabetes among preterm births may indicate that clinicians most often succeed in their care for women with type 1 diabetes delivering early, and for their preterm born babies. Yet, stratified analyses like the current one should be interpreted with caution because the interpretation depends on the true causal structure among many related variables [22]. The high proportion of pre-eclampsia occurring preterm in women with diabetes is in itself a challenge [23]. However, this might partly explain the relatively low mortality risk in preterm diabetes deliveries compared with the background population, in which a higher proportion of preterm births might be due to serious conditions less easily detected or intervened in.

While there were 15 cases of death in the term diabetes group (10 of them stillbirths), the expected number would be four if the risk equalled that of the background population. Six of these 15 had a gestational age (LMPbased) of 40 weeks or more. A Danish study exploring 25 cases of stillbirth in women with type 1 diabetes in the 1990s found no explanation, or suboptimal glycaemic control as the only explanation, in four out of six stillbirths to term [24]. Decisions by clinicians regarding whether and when to initiate delivery in women with type 1 diabetes are crucial and will always be a central part of the important care along these pregnancies. The National Institute for Health and Clinical Excellence (NICE) guidance recommends that all women with diabetes are offered elective birth after 38 completed weeks (induction of labour or, if indicated, elective Caesarean section) [25]. The ADA states that: 'an emerging consensus suggests that well-monitored diabetic women achieving excellent glycaemic control without obstetrical complications can await spontaneous labour up to 39-40 weeks gestation' [26]. In Norway, the national guidelines from 2008 recommend induction of women with pregestational diabetes around 40 weeks if no circumstances indicate earlier delivery or Caesarean section [27]. The current practice is that women with pregestational diabetes are offered labour induction between 38 and 40 completed weeks of pregnancy (T. Henriksen and S. Vangen, personal communication). Our findings support the need for thorough consideration regarding women with type 1 diabetes approaching term, hinting also towards the need to consider both LMP and ultrasound-based term, in women with a discrepancy between the two term dates. We are worried that the pendulum has gone too far in allowing women with type 1 diabetes with otherwise uncomplicated pregnancy to deliver at a high gestational age.

Conclusions In conclusion, the three- to fourfold increased risk of stillbirth and perinatal death in women with type 1 diabetes represents a major challenge. Our novel finding that the excess risk was confined to term births is 
noteworthy. We believe there is a potential for better outcome by further improvement of care and optimised metabolic control for these women.

Acknowledgements The study was supported by research grants from the South-Eastern Norway Regional Health Authority, Oslo Diabetes Research Centre, and the Norwegian Research Council (for initiation of the study).

Contribution statement LCS and GJ were responsible for conception and design; IE and LCS were responsible for data analysis; IE, LCS and SV drafted the manuscript; all authors were involved in data interpretation, revised the manuscript for important intellectual content and gave final approval of the manuscript.

Duality of interest The authors declare that there is no duality of interest associated with this manuscript.

\section{References}

1. Persson M, Norman M, Hanson U (2009) Obstetric and perinatal outcomes in type 1 diabetic pregnancies - a large, population-based study. Diabetes Care 32:2005-2009

2. Macintosh MC, Fleming KM, Bailey JA et al (2006) Perinatal mortality and congenital anomalies in babies of women with type 1 or type 2 diabetes in England, Wales, and Northern Ireland: population based study. BMJ 333:177

3. Jensen DM, Damm P, Moelsted-Pedersen L et al (2004) Outcomes in type 1 diabetic pregnancies: a nationwide, population-based study. Diabetes Care 27:2819-2823

4. Evers IM, de Valk HW, Visser GH (2004) Risk of complications of pregnancy in women with type 1 diabetes: nationwide prospective study in the Netherlands. BMJ 328:915

5. Eidem I, Stene LC, Henriksen T et al (2010) Congenital anomalies in newborns of women with type 1 diabetes: nationwide population-based study in Norway, 1999-2004. Acta Obstet Gynecol Scand 89:1403-1411

6. Taylor R, Davison JM (2007) Type 1 diabetes and pregnancy. BMJ 334:742-745

7. Melamed N, Hod M (2009) Perinatal mortality in pregestational diabetes. Int J Gynaecol Obstet 104(Suppl 1):S20-S24

8. Rush RW, Keirse MJ, Howat P, Baum JD, Anderson AB, Turnbull AC (1976) Contribution of preterm delivery to perinatal mortality. Br Med J 2:965-968

9. Joner G, Stene LC, Søvik O (2004) Nationwide, prospective registration of type 1 diabetes in children aged $<15$ years in Norway 1989-1998: no increase but significant regional variation in incidence. Diabetes Care 27:1618-1622

10. Joner G, Søvik O (1989) Increasing incidence of diabetes mellitus in Norwegian children 0-14 years of age 1973-1982. Diabetologia 32:79-83
11. Joner G, Søvik O (1991) The incidence of type 1 (insulindependent) diabetes mellitus 15-29 years in Norway 1978-1982. Diabetologia 34:271-274

12. Norsk gynekologisk forening (2008) Veileder i fødselshjelp, kapittel 24. Available from http://legeforeningen.no/id/131771.0 . Accessed 1 April 2011 [in Norwegian].

13. Casson IF, Clarke CA, Howard CV et al (1997) Outcomes of pregnancy in insulin dependent diabetic women: results of a five year population cohort study. Br Med J 315:275-278

14. Cnattingius S, Berne C, Nordström ML (1994) Pregnancy outcome and infant mortality in diabetic patients in Sweden. Diabet Med 11:696-700

15. Penney GC, Mair G, Pearson DW (2003) Outcomes of pregnancies in women with type 1 diabetes in Scotland: a national populationbased study. BJOG 110:315-318

16. Platt MJ, Stanisstreet M, Casson IF et al (2002) St Vincent's Declaration 10 years on: outcomes of diabetic pregnancies. Diabet Med 19:216-220

17. Chappell L, Poulton L, Halligan A, Shennan AH (1999) Lack of consistency in research papers over the definition of pre-eclampsia. Br J Obstet Gynaecol 106:983-985

18. Greene MF, Hare JW, Krache M et al (1989) Prematurity among insulin-requiring diabetic gravid women. Am J Obstet Gynecol 161:106-111

19. Melamed N, Chen R, Soiberman U, Ben-Haroush A, Hod M, Yogev Y (2008) Spontaneous and indicated preterm delivery in pregestational diabetes mellitus: etiology and risk factors. Arch Gynecol Obstet 278:129-134

20. Lauszus FF, Fuglsang J, Flyvbjerg A, Klebe JG (2006) Preterm delivery in normoalbuminuric, diabetic women without preeclampsia: the role of metabolic control. Eur J Obstet Gynecol Reprod Biol 124:144-149

21. Kramer MS, Demissie K, Yang H, Platt RW, Sauve R, Liston R (2000) The contribution of mild and moderate preterm birth to infant mortality. Fetal and infant health study group of the canadian perinatal surveillance system. JAMA 284:843-849

22. Hernandez-Diaz S, Schisterman EF, Hernan MA (2006) The birth weight "paradox" uncovered? Am J Epidemiol 164:1115-1120

23. Jensen DM, Damm P, Ovesen P et al (2010) Microalbuminuria, preeclampsia, and preterm delivery in pregnant women with type 1 diabetes: results from a nationwide Danish study. Diabetes Care 33:90-94

24. Lauenborg J, Mathiesen E, Ovesen P et al (2003) Audit on stillbirths in women with pregestational type 1 diabetes. Diabetes Care 26(5):1385-1389

25. Guideline Development Group (2008) Management of diabetes from preconception to the postnatal period: summary of NICE guidance. BMJ 336:714-717

26. Kitzmiller JL, Jovanovic L, Brown F, Coustan D, Reader DM (2008) Managing preexisting diabetes and pregnancy: technical reviews and consensus recommendations for care. American Diabetes Association, Alexandria, p 585

27. Norsk gynekologisk forening (2008) Veileder i fødselshjelp, kapittel 8. Available from http://legeforeningen.no/id/131704.0. Accessed 1 April 2011 [in Norwegian]. 